\title{
Contributions of Grand Linguistic Theories to Second Language Acquisition Research and Pedagogy
}

\author{
Mohammad Alimohammadirokni ${ }^{1}$ \\ ${ }^{1}$ English Department, Faculty of Foreign Languages, University of Tehran, Tehran, Iran \\ Correspondence: Mohammad Alimohammadirokni, English Department, Faculty of Foreign Languages, \\ University of Tehran, Tehran, Iran. E-mail: mohammadalimohammadi@yahoo.com
}

\author{
Received: October 11, 2015 Accepted: October 31, 2015 Online Published: November 30, 2015 \\ doi:10.5539/ijel.v5n6p95 URL: http://dx.doi.org/10.5539/ijel.v5n6p95
}

\begin{abstract}
Research on second language acquisition (SLA) and use has always been enriched by linguistic schools and theories. The purpose of the present paper is give readers a snapshot of contributions grand linguistic theories have made to L2 acquisition research and pedagogy. The grand linguistic theories chosen for review in the present study include Structural Linguistics, Nativism, Functional Linguistics, and Cognitive Linguistics. These four linguistics theories have been, and some of them are, paid much more focus in the field of linguistics than other theories. In fact, the areas of SLA research and pedagogy have been highly influenced by these four grand linguistic theories. However, their impacts on these two areas have not been equal and, as a matter of fact, some of linguistic theories have more influenced SLA research while other theories have had implications more for SLA pedagogy. The contributions of the aforementioned grand linguistic theories to SLA research and pedagogy are discussed, along with criticisms against the contributions of each linguistic theory posed by the rival researchers.
\end{abstract}

Keywords: grand linguistic theories, second language acquisition, Structural Linguistics, Nativism, Functional Linguistics, and Cognitive Linguistics

\section{Introduction}

Language acquisition has always been seen as an interesting phenomenon for investigation as it was thought that its study would open a way for understanding the nature of human beings. In fact, the study of language has a history comparable to the study of philosophy, fine arts, and literature (see, for example, Formigari, 2004). Yet, such efforts have not always been philosophical, with some branches of linguistics trying to find solution to language-related problems in the real world. These branches constitute a family of subfields of linguistics, together named as Applied Linguistics. The field of Applied Linguistics is defined as "the academic discipline concerned with

the relation of knowledge about language to decision making in the real world" (Cook, 2003, p. 5). The decisions are made with respect to a wide range of language-related problems including aphasia, forensic investigations, (critical) discourse analysis, journalism, L2 teaching and learning, etc.

It would not raise a lot criticism to claim that the most studied member of the field of applied linguistics is second language acquisition (SLA) research and pedagogy which deals with the processes that are involved in the second language (L2) acquisition and use, with the practical objective of improving these processes. Any branch of applied linguistics has no choice but to resort to its mother (i.e., linguistics) as, in whatever phenomenon language is concerned, linguistics has something to offer to help us better understand that phenomenon. Again, it could be claimed that SLA has benefited most from linguistic theories. This is so because many linguistic theories proposed for explaining first language acquisitions either had implications for studying L2 acquisition and use or were subjected to experimentations to see if their propositions could explain aspects of L2 acquisition and use.

In the present review paper, the contributions that linguistic theories have made to SLA research and pedagogy are discussed. Since it would be difficult to put limit to linguistic theories and to the contributions that they have made to SLA research and pedagogy, the present review has been necessarily selective. That is, it has only reviewed the contributions that four grand linguistic theories have made to SLA research and pedagogy. The four linguistic theories of interest to be discussed included Structural Linguistics, Nativism, Functional Linguistics, 
and Cognitive Linguistics. The contributions of these linguistic theories to SLA have been of different degrees and types. Some of them have more influenced SLA research, others have had implications more for SLA pedagogy, and, yet, some others have influenced both. At the end of the review, some suggestions are made as to how SLA research and pedagogy should interact with linguistic theories in the future.

\section{Structural Linguistics}

Perhaps, the first systematic attempts to study the nature of language were those made by the so-called structural linguists. Structural Linguistics was founded on the belief that the core of language knowledge is structure, or pattern, and that language speakers learn to use these structures/patterns in pre-determined language use contexts (see Richards \& Rodgers, 2001). This belief originated from the linguistics interests of the 1950s "[a]s linguists discovered new sound types and new patterns of linguistic invention and organization, [and, therefore,] a new interest in phonetics, phonology, morphology, and syntax developed" (p. 54). So, the structural linguistics began to undertake efforts to study the phonological, morphological, and syntactic organizations of a wide range of languages all over the world. Another important premise of Structural Linguistics was that every language has its own particular system of structures and that no presuppositions could be made about the structural patterns of any language in the world. The duty of a structural linguist was to study the structural patterns of a language before he/she could make generalizations on its structural system. In the 1950s and 1960s, this idea was associated with the empiricist proposition that children are born with no presuppositions about the world and that they are conditioned to particular behaviors through stimulus-response associations they learn in the environment. This association between the Structural Linguistics and the empiricist learning school of behaviorism had important implications for SLA research and pedagogy of the time which would be discussed later.

In the meantime, the ideas of Structural Linguistics were vigorously embraced by language teaching practitioners, especially those who followed an Audiolingual approach to teaching second languages. Language classrooms of the time were characterized by language teachers having their students to practice hundreds (or even thousands) structural patterns of the L2. The logic behind these hardworking practice assignments was that language learners should be equipped with the ability to make use of L2 structural patterns in language use situations. Further, the order in which these structures were presented to the students was established by a contrastive analysis (see below) between the learners' L1 and L2.

\subsection{Priority of Spoken Language over Written Language}

A distinguishing feature of Structural Linguistics was that it claimed spoken language to be the primary form of a language and considered written language as subsidiary to spoken language (Brooks, 1964). This belief of the structural linguists had a historical root (see Richards \& Rodgers, 2001). At a time, the structural linguists' minds were preoccupied with describing languages which lacked writing systems. These languages belonged to the native Indians and their study was appealed to the structural linguists who wanted to investigate the distinguishing structures of these languages. So, the structural linguists had no other choice but to resort oral data they gathered from the native speakers of these languages Systematic designs were developed for gathering oral data from the native speakers (Richards \& Rodgers, 2001). This historical tradition drove the structural linguists to announce that spoken language is the primary, natural from of the language whereas the written language is an artificial craft derived from the primary form (i.e., spoken language) and is, thus, subsidiary to the primary form.

The above-mentioned premise had profound implications for SLA pedagogy. It was suggested that language learning should commence with a focus on the spoken language; written language should only be taught at the later stages of L2 teaching when L2 oral skills have been acquired. More importantly, whatever written language learners learned was based on the spoken language they had already practiced. Spoken L2 was taught through drilling practice techniques such as repetition, replacement integration, completion, restoration, etc. (see Richards \& Rodgers, 2001, pp. 60-62, for a rather full list of these drilling practice techniques). Once learners' L2 proficiency achieved high levels of L2 spoken through such techniques, they were then required to copy written sentence models they had previously orally practiced.

\subsection{Contrastive Analysis Hypothesis}

As mentioned above, the proponents of Structural Linguistics claimed that each language had its own particular language structure and, therefore, presuppositions could not be made about the structure of any language until it would be meticulously studied. In the mean time, this claim was associated with the proposition that language is a verbal behavior (Skinner, 1957). The implication of thinking of language as a verbal behavior was that, like any other human behavior, its learning may be intervened by the learning or use of other behaviors. As far as L2 learning was concerned, this meant that language learners should be kept away from the structural patterns of their own mother tongue so that the structures of the two languages did not intervene with each other when 
learning and using the L2. Therefore, in learning an L2, learners should be discouraged to use their mother tongue in the process of L2 learning (Larsen-Freeman \& Anderson, 2013; Richards \& Rodgers, 2001).

The above proposition had a profound implication for the fields of SLA research and pedagogy. A new area of investigation called Contrastive Analysis Hypothesis (CAH) came into the scene. To avoid intervention between L1 and L2 structures for the learners, research and pedagogical attempts went to conduct contrastive analyses between dozens of languages. A number of hierarchies of L2 structural difficulties were proposed by the SLA researchers following two aims. The first aim was to predict in learning what L2 structures learners from a particular L1 would experience difficultly. This was determined by identifying language areas where there was differences between L1 and L2 structures. The second aim was to order the identified difficulties so that the order of their presentation in language classrooms would be predetermined. The criterion set here was that the larger the difference between an L1 item and an L2 item was, the greater was the difficulty for the language learner to learn the L2 item. The CAH hierarchies proposed (e.g., Prator, 1967; Stockwell, Bowen, \& Martin, 1965) were then used by the L2 practitioners as a guide for teaching L2 structures (Brown, 2000).

"The starting point is a linguistic syllabus, which contains the key items of phonology, morphology, and syntax of the language arranged according to their order of presentation. These may have been derived in part from a contrastive analysis of the differences between the native language and the target language, since these differences are thought to be the cause of the major difficulties the learner will encounter" (Richards \& Rodgers, 2001, p. 59)

However, the principles of the structuralist approaches to SLA were criticized by the opponents in the field. These opponents attacked the structuralist approaches to SLA on the ground that, though structure is essential to language knowledge, it is meaning that constitutes the basic core of language knowledge. Further, post-structuralist SLA researchers and practitioners contended that there was no need to prioritize L2 skills as L2 skills could be taught simultaneously or should be taught according to the learners' needs. The status of CAH was also harshly attacked. SLA researchers found that many of language errors predicted by CAH hierarchies to happen were not actually observed to happen in language classrooms. In addition, many of language errors observed in language classrooms did not arise from differences between the L1 and the L2 but had a root in either the L2 itself or other factors (e.g., the context of language learning, communication strategies, etc. (see Jaszczolt, 1995; Richards, 1974).

\section{Nativism}

Nativism (also known as Generative Linguistics) is a linguistic school which has been mainly formed based on the ideas posed by the famous American linguist, Noam Chomsky. Chomsky $(1959,1965)$ criticized the linguistic ideas of his time which took an empiricist approach to the study of language. According to these empiricist ideas, language knowledge consists of a series of stimulus-response associations which the child learns from the surrounding language environment during the process of growth (Skinner, 1957). Chomsky harshly attacked these empiricist ideas by stating that many aspects of language knowledge are endowed to the child at the birth (or even before birth) and, therefore, he called for a coherent linguistic theory which could account for inborn language knowledge. To provide evidence for his claim, Chomsky proposed the argument of Poverty of the stimulus (also known as the logical problem of language acquisition. According to the argument, the input data that the child receives from the surrounding environment (i.e., positive evidence) cannot explain for language knowledge (Tomasello \& Tomasello, 2009). Though language speakers get no clue as to whether some sentences are grammatically ill-formed from the positive evidence, when they are required to make such a judgment, they would be successful in their judgments. According to Chomsky, this shows that children are born with some innate language knowledge which is present in their mind even before they get any language exposure from the surrounding environment.

Another premise of Generative Linguistics is that two sets of language rules constitute rules of language knowledge and that both sets are innate in nature. Together, these two sets of rules constitute Universal Grammar (UG) which is defined as language rules which are applicable to all language over the world (Trask, 2007). The first set includes universal principles which are language rules that constrain the way the structural system of a language works (Chomsky, 1980, 1981). As the name speaks for itself, universal principles are operative with respect to the all languages all over the world as they emerge from the neurobiological structures of the mind and, thus, cannot be breached. Examples of universal principles are the following (from Trask, 2007, p. 311):

- Every language distinguishes nouns and verbs,

- every language distinguishes three persons, and 
- $\quad$ every language has at least three vowels

The second set of language rules are called language parameters. Language parameters constrain the structural system of a language too. But, unlike universal principles, language parameters are those rules which can explain the structural variations among the world's languages. Parameters provide each language with options (called settings); i.e., each language parameter should be set in one way or the other by the child according to the input data that he/she receives from the surrounding environment. One example of language parameters is whether allows head-initial phrases or head-final phrases. 'Head' is the component around which a phrase is formed. For instance, the head of a noun phrase is a noun and the head of a verb phrase is a verb. The head parameter specifies the order of the components of a phrase with respect to the head of the phrase. For example, English is a head-initial language whereas Japanese is a head-final language (Cook \& Newson, 2014).

The linguistic school of Nativism has appealed much to the interest of SLA researcher. These researchers were particularly interested in two lines of research. First, they wanted to see whether language learners had access to universal principles and language parameters (i.e., UG) when learning an L2. Second, they aimed to determine whether the innate capability to learn a language would still exist when learning the L2.

\subsection{UG-Access Studies of L2 Acquisition}

Chomsky's ideas on UG was immediately introduced into the field of SLA, particularly as a reaction to the then-believed claim that language learners would not benefit from their previous language knowledge (i.e., knowledge of their mother tongue) in acquiring the L2. This claim was propagated by those following and practicing the principles of Audiolingualism in the field of L2 teaching. In fact, these individuals believed that not only L1 would not help to acquiring the L2 but also its use should be limited in L2 classrooms so that its structures did not intervene with L2 structures. However, the SLA proponents of Chomsky's ideas contended that there are many aspects of language knowledge shared by all the languages in the world and, therefore, the language learner does not need to begin the process of language learning from the scratch. In other words, the proponents of a Chomskyan approach to SLA believe that "L1 grammar forms the interlanguage initial state" (White, 2003, p. 87). The position goes on that then UG principles and parameters come into play to form this initial state into the ultimate interlanguage system (Felix, 1988; Kanno, 1998; White, 2003).

The question remained to be answered is how much the language learner has access to these principles and parameters. In fact, the L2 researchers working under a generative linguistics framework are far from being unanimous when it comes to answer this question. These researchers are grouped into three camps when answering the question; i.e., Full Access Hypothesis, Partial Access Hypothesis, and No-access Hypothesis (see White, 2003).

According to the first proposition, Full Access Hypothesis, all the universal principles are available to the person when he/she is learning the L2 (Schwartz, 1998; Schwartz \& Sprouse, 1996). This means that the necessary structural prerequisites are available to the language learner even before he/she begins the process of L2 acquisition (Schwartz, 1998). The important point is that the learner has access to the UG principles without any mediation from his/her L1. Partial Access Hypothesis too supports the availability of UG principles to the language learner; however, the hypothesis argues that the availability happens through the mediation of the learner's L1 (Hawkins \& Chan, 1997; Schachter, 1989). Further, Partial Access Hypothesis states that L1 mediates the setting of language parameters when one is learning the L2. If a particular language parameter is set the same way in the L1 and the L2, the learner does not need to reset the parameter when learning the L2; that is, the parameter setting is transferred from the L1 knowledge to L2 acquisition, making the learner's duty easier. However, when a language parameter is set differently in the L1 and the L2, the learner needs to reset the parameter when learning the L2 (Schachter, 1989). So, the learner's access to UG principles and parameters is partial and mediated by the L1 structures. The last hypothesis, No-access Hypothesis, argues that adult language learners do not have access to UG principles and parameters which make L2 acquisition more difficult than L1 acquisition since L2 learners cannot be helped by their innate language abilities any longer (see Epstein, Flynn, \& Martohardjono, 1996). According to the supporters of No-access Hypothesis, this can explain why L2 learners are usually unsuccessful in their attempts to acquire the L2 because the UG window has been closed for them after the critical period of puberty (see the next section).

\subsection{Critical Period Hypothesis}

It is defendable to claim that the linguistic school of Nativism has most strongly influenced SLA research through the Critical Period Hypothesis (CPH). The CPH refers to the hypothetical proposition that learning a language is restricted by maturational constraints, meaning that language learning is possible until a certain age 
(i.e., after puberty; Lenneberg, 1976). According to Lenneberg (1976), after this certain age has passed, it would be really difficult to acquire a language.

The $\mathrm{CPH}$ manifested to have significant implications for both SLA research and pedagogy. As far as its implication for SLA research is concerned, many learners start their language learning efforts after they have passed puberty and, therefore, the question arises as to whether L2 acquisition is possible for these learners at all and, if so, how much. For SLA pedagogy, the implication is that what age range is the most appropriate age range for starting L2 learning so that the best could be achieved from language learning efforts. As far as the first aim is concerned, a lot of research has been done in the SLA literature to test the plausibility of the CPH for L2 acquisition (e.g., Birdsong \& Molis, 2001; DeKeyser, 2000; Hakuta, Bialystok, \& Wiley, 2003; Johnson \& Newport, 1989, 1991). These studies have been undertaken with the purpose of determining whether age would act as a maturational constraint on L2 acquisition and use processes and, if so, to provide explanations as to why that is the case. For example, Johnson and Newport (1989) conducted a study to investigate whether age would have effects on L2 learners' access to universal principles. The universal principle the researches targeted as the focus of their study was the principle of subjacency "which prevents a wh-phrase from moving 'too far' from its original position" (White, 2003, p. 121). In fact, Johnson and Newport (1991) conducted their study to see whether L2 learners' ability to recognize violations of the principle of subjacency was dependent on their maturational status (i.e., age). Their resylts showed that the L2 learners who started L2 learning in older ages were less able to recognize English subjacency violations than those who started L2 learning earlier in childhood.

DeKeyser (2000) was another study which investigated the age effects on L2 acquisition. Yet, unlike Johnson and Newport (1991), DeKeyser (2000) included a wider range of L2 (English) grammatical structures in his dependent measure of L2 knowledge. This made DeKeyser's findings on age effects on L2 grammatical development more generalizable to discussions of the CPH. DeKeyser's results showed that the younger language learners in his study were more successful in performing on the grammatical judgment test (i.e., the dependent measure) than the older language learners. This finding of DeKeyser's supports the credibility of the $\mathrm{CPH}$. Another important finding of DeKeyser's study was that the effects of maturational constraints on L2 acquisition were mediated by the participants' L2 acquisition aptitude. That is, the adult learners with higher L2 aptitude in DeKeyser's study were more successful in performing on the grammatical judgment test than the adult learners with lower L2 aptitude. This shows that the age effects have a significant interaction with other variables as far as L2 acquisition is concerned. This conclusion has been supported by other researchers investigating age effects on L2 acquisition (e.g., Abrahamsson \& Hyltenstam, 2008).

The relevance of Chomsky's ideas for SLA pedagogy has been harshly attacked by some researchers. For example, De Bot (2015) questions the relevance of generative linguistic ideas for SLA pedagogy by arguing that "[i]ts premises have lost their weight for the SLA community, and now other approaches are taking over" (pp. 261-263). However, De Bot's attack to UG-based L2 studies have not left unanswered. Slabakova, Leal, \& Liskin-Gasparro (2015) presented a counterargument to De Bot's criticism of UG-based SLA framework by saying that "the goal of this framework has never been to address pedagogical concerns"(p. 265). We need to wait to see whether Chomsky's ideas would continue to contribute to SLA research in the future and could also provide practical implications for SLA pedagogy.

\section{Functional Linguistics}

Functional Linguistics has been an attempt to explain language use in appropriate contexts (see Halliday, 1973; Hymes, 1972; Matthiessen, Teruya, \& Lam, 2010). According to functional linguists, knowledge of language grammar is but just one aspect of overall language knowledge and, therefore, structuralist or generative-linguistic theories cannot account for language knowledge as it is represented in the language speaker's mind. As you noticed in the above paragraphs, structuralist and nativistic linguists contended that the speaker's responsibility is to either produce or comprehend grammatically well-formed sentences. The functional linguists, however, contended that knowledge of grammatical structures alone cannot explain how speakers are able to produced and comprehend appropriate utterances in communication contexts. This proposition led the linguists of the time to investigate what other competences beyond the grammatical knowledge are necessary for successful communication. Most of these attempts were undertaken by SLA researchers who aimed to propose coherent models of L2 communicative competence. Since then, these models have been applied in teaching L2s. Further, Functional Linguistics has help to the emergence of a subfield in the realm of SLA known as Interlanguage Pragmatics. This subfield aims to investigate the acquisition and use of the so-called language functions. 


\subsection{Models of L2 Communicative Competence}

The most important contribution of Functional Linguistics to the areas of SLA research and pedagogy has been through the introduction of communicative competence. The term was introduced by Hymes (1972) who stated that, even though Chomsky was successful in presenting an attractive theory of language knowledge, Chomsky's UG model underrepresented this knowledge as it neglected aspects of language knowledge that were essential to language communication. Particularly, Hymes stressed that one vital aspect of language knowledge is that speakers should have the ability to use language knowledge appropriately, meaning that the speaker should take the contextual factors in which the communication happens into consideration.

This idea was appealed to SLA researchers and practitioners who had already noticed that knowledge of grammar alone would not guarantee successful L2 communication. So, attempts were made by these individuals to propose coherent models of L2 communicative competence. Two of the most famous of such models are those proposed by Canale and Swain (1980) and Bachman (1900). In a groundbreaking article and a follow-up update, Canale and Swain (1980) and Canale (1983) suggested that L2 communicative competence consists of four compartments; i.e., grammatical competence, sociolinguistic competence, discourse competence, and strategic competence. These four components of L2 communicative competence can be defined as the following:

- Grammatical competence: This competence is equal to Chomsky's language competence and includes knowledge of such language aspects as phonetics, phonology, morphology, and syntax. Grammatical competence is responsible for producing and comprehending syntactically well-formed sentences/utterances.

- Sociolinguistic competence: This competence is responsible for consideration of sociocultural contexts when using the L2. This includes considering the roles of communication interlocutors, the place, purpose, and genre of communication, the sociolinguistic setting in which communication happens, etc. as Canale and Swian (1980) and Canale (1983) contend, these factors determine the speakers' choices over language forms and the hearer's

- Discourse competence: This dimension of communicative competence deals with the production and comprehension of language stretches above sentence. As Canale and Swian (1980) state, linguistic competence cannot explain how speakers go to processing connected sentences as extrasentential structures are not produced by the linguistic competence alone.

- Strategic competence: This competence includes the set of L2 communication strategies. Communication strategies can be defined as strategies L2 learners employ when their L2 knowledge fails them in the process of L2 communication. In other words, these communication strategies can compensate for the gaps in the learner's knowledge of L2. Examples of such communication strategies are word coinage, circumlocution, code-switching, prefabricated phrases, etc. (Dörnyei, 1995).

Another model of L2 communicative competence has been also proposed by Bachman (1990). The difference between Canale and Swian's (1980) model and Bachman's (1990) model is that the components in Canale and Swian's model, except for strategic competence, are together entitled as language competence, with the components in Canale and Swian's model termed differently in Bachman's model even though there are also some disparities in content between the two models. According to Bachman's model, language competence consists of two dimensions of organizational competence and pragmatic competence. Each of these two dimensions is further categorized into two subdimensions. The organizational competence consists of grammatical competence and textual competence, the latter subdimension being equal to Canale and Swian's discourse competence. In addition, the pragmatic competence consists of illocutionary competence and sociolinguistic competence. Bachman's model of L2 communicative competence takes this language competence to incorporate in a more general model which is entitled communicative language ability. Beside language competence, communicative language ability includes other components which are believed to help the L2 speaker communicate successfully in the L2. These other components are context of situation, psychophysiological mechanisms, knowledge structures, and strategic competence. In his model, the strategic competence plays a higher order role which manages and executes the process of L2 communication (see Bachman, 1990, pp. 85-87, for the graphic representation of the model).

The above two models of L2 communicative has been welcome by the SLA researchers and practitioners since their introduction to the field. They have highly influenced the SLA research and practice done since 1980s. Canale and Swain's (1980) model has appealed more to language teaching practitioners who came to realize that focus on grammatical competence alone does not guarantee that their students would be able to communicate in the L2 successfully. So, teachers tried to incorporate language teaching and learning activities into their classrooms that would improve different aspects of their learners' communicative competence. Bachman's (1990) 
model, on the other hand, has been more appealed to language testing practitioners as a yardstick for validating L2 tests purported to measure $\mathrm{L} 2$ communication abilities.

\subsection{Interlanguage Pragmatics}

Another SLA subfield emerging as a result of functional-linguistic approaches to the study of language involves research on the production and comprehension of language functions. This subfield is unanimously known as Interlanguage Pragmatics (ILP). Language functions are defined as language elements with which we do things. Examples of language functions are requesting, apologizing, suggesting, stating, complimenting, criticizing, etc. (see Bardovi-Harlig \& Hartford, 2005 for a comprehensive typology of language functions). The findings of the ILP research have provided fruitful insights for our understanding of the acquisition and use of L2 communication abilities in several directions.

First, the ILP research has help us understand that knowledge of L2 formal structures does not necessarily guarantee successful L2 communication (Bardovi-Harlig, 1999; Kasper, 2001). According to Bardovi-Harlig (1999), "high levels of grammatical competence do not guarantee concomitant high levels of pragmatic competence" (p. 686). The implication of this fining for SLA pedagogy is that language teaching and learning efforts should be focused on developing L2 learners' knowledge and use of L2 functions as self-contained undertaking. Second, the ILP researcher has help L2 researchers and practitioners notice that language teaching and learning activities that are group-based in nature are more effective in improving L2 learners' L2 communication abilities than activities that which require the learner to practice L2 communication abilities in isolation (Ohta, 2005). The argument for this proposition is that group-based language activities provide a context in which the learner has the chance to learn what communication factors he/she needs to take into consideration when producing and comprehending L2 functions.

Third, ILP studies have contributed to our understanding of the cognitive processes involved in SLA. ILP researchers have come to recognize that the acquisition of ILP knowledge is governed by cognitive processes different from those involved in the acquisition of formal aspects of L2 knowledge. Though the acquisition of formal L2 aspects is better achieved through language teaching and learning techniques which demand the learner's focal consciousness, ILP skills are better advanced through activities that rely on the learner's peripheral attentions (see, for example, Bardovi-Harlig, 1999; Kondo, 2008); however, in both cases, it is necessary that the learner's mental consciousness be focused on the structure to be learned (Schmidt, 1993).

\section{Cognitive Linguistics}

Cognitive Linguistics is a newcomer to the field of linguistics; however, it has been influential enough in the field of linguistics to claim full volumes (e.g., Croft \& Cruise, 2004; Evans \& Green, 2006; Geeraerts \& Cuyckens, 2007) and prestigious journals for its domains (Cognitive Linguistics and Annual Review of Cognitive Linguistics). According to Evans and Green (2006) Cognitive Linguistics deals with the cases of language phenomena in which language and cognition intersect. In other words, Cognitive Linguistics is more concerned with the psychological processes involved in language acquisition and use. It took only a few years before the theories and ideas proposed by cognitive linguists were embraced by SLA researchers. Several volumes (e.g., Robinson \& Ellis, 2008; Tyler, 2012) were devoted to the implications that a cognitive linguistic approach would have for the processes of L2 acquisition use. In fact, SLA researchers had already recognized that a coherent theory of SLA needs take into consideration the cognitive processes involved in L2 acquisition as these processes are the most important determinants of L2 achievement or failure. SLA researchers have been long working under the frameworks of information-processing theory (McLaughlin, 1990; McLaughlin, Ross, \& McLeod, 1983). and noticing hypothesis (Schmidt, 1993), for example.

The contributions of Cognitive Linguistics to SLA research and pedagogy have been in several directions. A principal premise of Cognitive Linguistics is "that language is learned from usage" (Ellis \& Robinson, 2008, p. 5). This means that the frequency of the input learners receive is a main determinant of L2 acquisition and use. This premise has provoked a line of research the aim of which has been to compute the effects of input frequency on the acquisition of different L2 aspects. The results of this line of research has been that, though L2 structures are learned in predetermined, natural orders (Dulay, Burt, \& Krashen, 1982), these natural orders have an interplay with the frequency of the L2 input learners receive in that a learners should be exposed to a threshold of an L2 structure before it could be acquired. Further, the type and quality of the input that learners receive would also have differential effects on the ultimate outcomes of L2 acquisition. As Ellis and Robinson (2008) express, "fundamental properties of associative learning such as construction frequency, salience, redundancy, and exposure order affect learners' attention to language, thereby affecting the course and level of ultimate attainment in the L2" (p. 14). 
Another implication of Cognitive Linguistics has been for instructed language learning. The concept of cognitive grammar has an established status in the field of Cognitive Linguistics. Cognitive grammar refers to the idea that knowledge of grammar does not only consist of a network of grammatical constructions and restrictions; rather, the knowledge "makes a semantic contribution and every grammatical distinction has conceptual import" (p. 78). The implication of this premise of Cognitive Linguistics for SLA pedagogy has been that language teachers and practitioners should try to incorporate language teaching activities in their classrooms that let learners notice the associations between L2 language structures and their conceptual imports.

The implications that Cognitive Linguistics will have for L2 acquisition and use remain to be discovered. As the introduction of Cognitive Linguistics into SLA research and pedagogy has been rather new, it would be expected that more SLA research would be carried out based on cognitive linguistic frameworks. In return, such research would hopefully increase L2 teachers' and practitioner's understanding of the effective techniques and activities to teach an L2.

\section{Conclusion}

The contribution of the field of linguistics goes far beyond those mentioned in the current review paper. In fact, this paper had to be selective in discussing the contributions that the field of linguistics has made to SLA research and pedagogy; i.e., it only discussed the contributions that grand linguistic theories and frameworks have made to these SLA areas. However, even from the review presented in this paper, it is clear that these contributions have been very influential to both SLA research and pedagogy. In fact, these two areas are highly in need of coherent linguistic framework to help them understand the processes of SLA. Further, it goes without saying that these contributions would not stop here; SLA researchers continue to make use of the implications of theories and ideas that their counterparts are proposing in the field of linguistics. However, there are a few points that SLA researchers and practitioners should bear in mind when making use of linguistic theories in their own L2 research and practice. First, though different linguistic theories are proposed as contradictory schools of thoughts on language knowledge, SLA researchers and practitioners do not have to make use of the implications of one particular linguistic theory at the cost of those of other linguistic theories. So, it is recommended that these researchers and practitioners make use of the strengths of different linguistic theories in a complementary fashion to improve the outcomes of their L2 research and practice efforts. Second, it seems that SLA researchers have benefitted more from linguistic theories and ideas in their own research than have SLA practitioners in their own teaching practices (De Bot, 2015). This may explain why many SLA practitioners cast doubts on the practical implications of linguistic theories for their own classrooms. So, future studies should focus on the positive effects that linguistic theories can make to real-world L2 practice and pedagogy. Finally, it is proposed that the relationship between linguistic theories and SLA research become a two-way street. That is, SLA researchers should try to pay their own debts to linguistics' contributions through helping the field of linguistics better understand the processes of language acquisition.

\section{References}

Abrahamsson, N., \& Hyltenstam, K. (2008). The robustness of aptitude effects in near-native second language acquisition. Studies in Second Language Acquisition, 30, 481-509. http://dx.doi.org/10.1017/S027226310808073X

Bachman, L. F. (1990). Fundamental considerations in language testing. Oxford: Oxford University Press.

Bardovi-Harlig, K. (1999). Exploring the interlanguage of interlanguage pragmatics: A research agenda for acquisitional pragmatics. Language learning, 49(4), 677-713. http://dx.doi.org/10.1111/0023-8333.00105

Bardovi-Harlig, K., \& Hartford, B. (Eds.). (2005). Interlanguage pragmatics: Exploring institutional talk. Boston: Psychology Press.

Birdsong, D., \& Molis, M. (2001). On the evidence for maturational effects in second language acquisition. Journal of Memory and Language, 44, 235-249. http://dx.doi.org/10.1006/jmla.2000.2750

Brooks, N. (1964). Language and language learning: Theory and practice (2nd ed.). New York: Harcourt Brace.

Brown, H. D. (2000). Principles of language learning and teaching (4th ed.). New York: Longman.

Chomsky, N. (1959). Review of the book Verbal behavior. Language, 35, 26-58. http://dx.doi.org/10.2307/411334

Chomsky, N. (1965). Aspects of the theory of syntax. Cambridge, MA: Massachusetts Institute of Technology Press.

Chomsky, N. (1980). Rules and representations. Oxford: Blackwell. 
Chomsky, N. (1981). Principles and parameters in syntactic theory. In N. Hornstein \& D. Lightfoot (Eds.), Explanation in linguistics: the logical problem of language acquisition (pp. 32-75). London: Longman.

Cook, G. (2003). Applied linguistics. Oxford: Oxford University Press.

Cook, V., \& Newson, M. (2014). Chomsky's universal grammar. New York: John Wiley \& Sons.

Croft, W., \& Cruise, A. (2004). Cognitive linguistics. Cambridge: Cambridge University Press. http://dx.doi.org/10.1017/CBO9780511803864

De Bot, K. (2015). Moving Where? A Reaction to Slabakova et al. (2014). Applied Linguistics, 36(2), 261-264. http://dx.doi.org/10.1093/applin/amu074

DeKeyser, R. M. (2000). The robustness of critical period effects in second language acquisition. Studies in Second Language Acquisition, 22(4), 499-533.

Dörnyei, Z. (1995). On the teachability of communication strategies. TESOLQuarterly, 29, 55-84. http://dx.doi.org/10.2307/3587805

Dulay, H., Burt, M., \& Krashen, S. (1982). Language two. New York: Cambridge University Press.

Ellis, N. C., \& Robinson, P. (2008). An introduction to cognitive linguistics, second language acquisition, and language instruction. In P. Robinson \& N. C. Ellis (Eds.), Handbook of cognitive linguistics and second language acquisition (pp. 3-24). New York: Routledge.

Epstein, S., Flynn, S., \& Martohardjono, G. (1996). Second language acquisition: theoretical and experimental issues in contemporary research. Brain and Behavioral Sciences, 19, 677-758. http://dx.doi.org/10.1017/S0140525X00043521

Evans, V., \& Green, M. (2006). Cognitive linguistics: An introduction. Edinburgh: Edinburgh University Press.

Felix, S. (1988). UG-generated knowledge in adult second language acquisition. In S. Flynn \& W. O’Neil (Eds.), Linguistic theory in second language acquisition (pp. 277-294). Dordrecht: Kluwer. http://dx.doi.org/10.1007/978-94-009-2733-9_15

Formigari, L. (2004). A History of Language Philosophies (G. Poole, Trans.). Philadelphia: John Benjamins Publication. http://dx.doi.org/10.1075/sihols.105

Geeraerts, D., \& Cuyckens, H. (Eds.). (2007). The Oxford handbook of cognitive linguistics. Oxford University Press, USA.

Hakuta, K., Bialystok, E., \& Wiley, E. (2003). Critical evidence a test of the critical-period hypothesis for $\begin{array}{lllll}\text { second-language } \quad \text { acquisition. } & \text { Psychological } & \text { Science, } & \text { 14(1), }\end{array}$ http://dx.doi.org/10.1111/1467-9280.01415

Halliday, M. (1973). Explorations in the functions of language. London: Edward Arnold.

Hawkins, R., \& Chan, C. Y. H. (1997). The partial availability of Universal Grammar in second language acquisition: The 'failed functional features hypothesis'. Second Language Research, 13(3), 187-226. http://dx.doi.org/10.1191/026765897671476153

Hymes, D. (1972). On communicative competence. In J. B. Pride \& J. Holmes (Eds.), Sociolinguistics (pp. 269-293). Harmondsworth: Penguin Books.

Jaszczolt, K. (1995). Typology of contrastive studies: Specialization, progress, and applications. Language Teaching, 28, 1-15. http://dx.doi.org/10.1017/S0261444800000306

Johnson, J. S., \& Newport, E. L. (1989). Critical period effects in second language learning: The influence of maturational state on the acquisition of English as a second language. Cognitive psychology, 21(1), 60-99. http://dx.doi.org/10.1016/0010-0285(89)90003-0

Johnson, J., \& Newport, E. (1991). Critical period effects on universal properties of language: The status of subjacency in the acquisition of a second language. Cognition, 39, 215-258. http://dx.doi.org/10.1016/0010-0277(91)90054-8

Kanno, K. (1998). The stability of UG principles in second language acquisition. Linguistics, 36, 1125-1146. http://dx.doi.org/10.1515/ling.1998.36.6.1125

Kasper, G. (2001). Four perspectives on L2 pragmatic development. Applied linguistics, 22(4), 502-530. http://dx.doi.org/10.1093/applin/22.4.502 
Kondo, S. (2008). Effects on pragmatic development through awareness-raising instruction: Refusals by Japanese EFL learners. In E. Alcón \& A. Martínez-Flor (Eds.), Investigating pragmatics in foreign language learning, teaching and testing (pp. 153-177). Clevedon: Multilingual Matters.

Larsen-Freeman, D., \& Anderson, M. (2013). Techniques and Principles in Language Teaching (3rd ed.). Oxford: Oxford University Press.

Matthiessen, C., Teruya, K., \& Lam, M. (2010). Key terms in systemic functional linguistics. New York: Continuum.

McLaughlin, B. (1990). Restructuring. Applied Linguistics, 11, 113-128. http://dx.doi.org/10.1093/applin/11.2.113

McLaughlin, B., Ross, T., \& McLeod, B. (1983). Second Language learning: An information-processing perspective. Language Learning, 33, 135-158. http://dx.doi.org/10.1111/j.1467-1770.1983.tb00532.x

Ohta, A. S. (2005). Interlanguage pragmatics in the zone of proximal development. System, 33(3), 503-517. http://dx.doi.org/10.1016/j.system.2005.06.001

Prator, C. (1967). Hierarchy of difficulty. Unpublished classroom lecture, University of California, Los Angeles.

Richards, J. (1974). Error analysis: Perspectives on second language acquisition. London: Longman.

Richards, J. C., \& Rodgers, T. (2001). Approaches and methods in language teaching (2nd ed.). Cambridge: Cambridge University Press. http://dx.doi.org/10.1017/CBO9780511667305

Robinson, P., \& Ellis, N. C. (Eds.). (2008). Handbook of cognitive linguistics and second language acquisition. New York: Routledge.

Schachter, J. (1989). Testing a proposed universal. In S. Gass and J. Schachter (Eds.), Linguistic perspectives on second language acquisition (pp. 73-88). Cambridge: Cambridge University Press. http://dx.doi.org/10.1017/CBO9781139524544.007

Schmidt, R. (1993). Consciousness, learning and interlanguage pragmatics. In G. Kasper \& S. Blum-Kulka (Eds.), Interlanguage pragmatics (pp. 21-42). New York: Oxford University Press.

Schwartz, B. D. (1998). The second language instinct. Lingua, 106(1), 133-160. http://dx.doi.org/10.1016/S0024-3841(98)00032-1

Schwartz, B. D., \& Sprouse, R. A. (1996). L2 cognitive states and the full transfer/full access model. Second language research, 12(1), 40-72. http://dx.doi.org/10.1177/026765839601200103

Skinner, B. F. (1957). Verbal behavior. New York: Appleton-Century-Crofts. http://dx.doi.org/10.1037/11256-000

Slabakova, R., Leal, T., \& Liskin-Gasparro, J. (2015). Rumors of UG's demise have been greatly exaggerated. Applied Linguistics, 36(2), 265-269. http://dx.doi.org/10.1093/applin/amv007

Stockwell, R., Bowen, J., \& Martin, J. (1965). The grammatical structures of English and Spanish. Chicago: University of Chicago Press.

Tomasello, M., \& Tomasello, M. (2009). Constructing a language: A usage-based theory of language acquisition. Harvard University Press.

Trask, R. L. (2007). Language and linguistics: The key concepts. New York: Routledge.

Tyler, A. (2012). Cognitive linguistics and second language learning: Theoretical basics and experimental evidence. New York: Routledge.

White, L. (2003). Second language acquisition and universal grammar. Cambridge: Cambridge University Press. http://dx.doi.org/10.1017/CBO9780511815065

\section{Copyrights}

Copyright for this article is retained by the author(s), with first publication rights granted to the journal.

This is an open-access article distributed under the terms and conditions of the Creative Commons Attribution license (http://creativecommons.org/licenses/by/3.0/). 